\title{
EDITORIAL
}

\section{Infectious Diseases Continued to be the World's Core Challenge}

\section{Abraham Haileamlak, MD, Professor of Pediatrics and Child Health}

In the past one century, many new and powerful infectious diseases control measures have been developed including early detection, use of antimicrobials, surveillance, and vaccinations (1). Despite all these, leave alone in low and middle income countries, infectious diseases remained as a public health problem in the high income countries. Annually, over 13 million people die from it globally (2).

Additionally, the number of infectious diseases that spread from one corner of a country to other or to neighboring countries then to the rest of the world is growing. Some of several such occurrences in the past few decades includeSevere Acute Respiratory Syndrome (SARS) from China to the rest of the world, Cholera and Ebola in Africa, Influenza A in Saudi Arabia, and most recently, Zika from Brazil. And now, Plague epidemic is going on in Madagascar. Many countries are in constant worries that such deadly infectious diseases might be carried from one part of the world to them (3). Although member countries signed an international agreement to report outbreaks promptly to the World Health Organization and take steps to control them, the vast majority have not fully complied with the pledge. Despite the ups and downs, the international effort to combat infectious diseases is becoming better.

Therefore, controlling communicable disease remains a vital battle in the war for the public's health. Before a century, isolation and hand washing were almost the only tools available to public health. Although the most successful interventions nowadays depend on vaccines, old traditional measures can still be a very effective means of control for some of such diseases (1).
The current issue, the last regular issue for the year, contains an editorial, eleven original articles, one case report and a letter to the editor. The editorial, six of the original articles, the case report and the letter to the editor focus on infectious diseases. The other articles and the case report over various topics.

I invite readers to go through these articles and appreciate or utilize the contents. I also encourage readers to forward comments and suggestions to the editor or the corresponding authors.

\section{REFERENCES}

1. Jim van Steenbergen, Ruth Gelletlie, Viviane Van Casteren. Communicable disease control still a core public health function. European Journal of Public Health 2006; 16 (2): 118. doi:10.1093/eurpub/ck1033

2. World Health Organization. Communicable disease prevention, control and eradication. http://www.who.int/countries/eth/areas/cd s/en/

3. Coping With Infectious Disease. The New York Times. https://www.nytimes.com/2014/02/22/opi nion/coping-with-infectious-disease.html

DOI: http://dx.doi.org/10.4314/ejhs.v27i6.1 